\title{
Development of Pellet Injection Systems for ITER
}

\author{
S. K. Combs, M. J. Gouge, L. R. Baylor, C. R. Foust, P. W. Fisher, S. L. Milora, \\ A. L. Qualls, D. E. Schechter, and J. M. Walters \\ Oak Ridge National Laboratory, P. O. Box 2009, Oak Ridge, TN 37831-8071
}

\section{DISCLAIMER}

This report was prepared as an account of work sponsored by an agency of the United States Government. Neither the United States Government nor any agency thereof, nor any of their employees, makes any warranty, express or implied, or assumes any legal liability or responsibility for the accuracy, completeness, or usefulness of any information, apparatus, product, or process disclosed, or represents that its use would not infringe privately owned rights. Reference herein to any specific commercial product, process, or service by trade name, trademark, manufacturer, or otherwise does not necessarily constitute or imply its endorsement, recommendation, or favoring by the United States Government or any agency thereof. The views and opinions of authors expressed herein do not necessarily state or reflect those of the United States Government or any agency thereof.

\section{Presented at the 16th IEEE/NPSS Symposium on Fusion Engineering \\ Champaign, Illinois \\ September 30 to October 5, 1995}




\title{
Development of Pellet Injection Systems for ITER ${ }^{*}$
}

\author{
S. K. Combs, M. J. Gouge, L. R. Baylor, C. R. Foust, P. W. Fisher, S. L. Milora, \\ A. L. Qualls, D. E. Schechter, and J. M. Walters \\ Oak Ridge National Laboratory, P. O. Box 2009, Oak Ridge, TN 37831-8071
}

\begin{abstract}
Oak Ridge National Laboratory (ORNL) has been developing innovative pellet injection systems for plasma fueling experiments on magnetic fusion confinement devices for about 20 years. Recently, the ORNL development has focused on meeting the complex fueling needs of the International Thermonuclear Experimental Reactor (ITER). In this paper, we describe the ongoing research and development activities that will lead to a ITER prototype pellet injector test stand. The present effort addresses three main areas: (1) an improved pellet feed and delivery system for centrifuge injectors, (2) a long-pulse (up to steady-state) hydrogen extruder system, and (3) tritium extruder technology. The final prototype system must be fully tritium compatible and will be used to demonstrate the operating parameters and the reliability required for the ITER fueling application.
\end{abstract}

\section{INTRODUCTION}

The purposes of the International Thermonuclear Experimental Reactor (ITER) fueling system [1] are to control the plasma ion density in order to maintain the fusion power at a specified level, to replenish the fuel burned in the deuteriumtritium (D-T) reaction, and to establish a flow of hydrogenic ions into the scrape-off layer to reduce the level of plasma impurities and helium ash. The ITER fueling system will use a combination of gas puffing and pellet injection to achieve and maintain ignited plasmas. The combination of gas and pellet fueling will provide a flexible source with D-T pellets penetrating beyond the separatrix to sustain the ignited fusion plasma and deuterium-rich gas fueling the edge region to meet divertor requirements.

While great progress has been made in the area of pellet injector technology at ORNL and around the world during the last decade [2-4], additional development is required to meet the fueling needs of ITER and future fusion reactors. The baseline ITER pellet injector concept is the centrifuge acceleration device. Centrifuge pellet injection systems are currently in operation on ASDEX-U and Tore Supra, with a system also under development for use on the Joint European Torus (JET). This acceleration technique has two distinct inherent advantages over other acceleration schemes. First, it can operate at high repetition rates by virtue of the inherent high rotational speeds of the accelerator arbor. Hence, the pellet delivery rate

\footnotetext{
* Research sponsored by the Office of Fusion Energy, U.S. Department of Energy, under contract DE-AC05-840R21400 with Lockheed Martin Energy Systems, Inc.
}

is limited by the rate at which material can be fed to the accelerator. Present devices typically operate at pellet frequencies in the 5- to $40-\mathrm{Hz}$ range with nominal pellet diameters of 1 to $3 \mathrm{~mm}$. When compared with light gas guns, the other advantage is that there is no driver propellant gas to handle, process, and recover. Presently, the single-stage light gas gun is the alternate/backup acceleration technique for ITER. Pneumatic injectors have demonstrated the reliability approaching that needed for ITER [5] and the larger pellet sizes (up to 8-mm diam) that may be needed for efficient and flexible operation on ITER. Operation with pellets $>3 \mathrm{~mm}$ has yet to be demonstrated with the centrifuge accelerator. With some of these issues unresolved and given the complimentary capability of the two acceleration methods, it is planned to keep both centrifuge and pneumatic acceleration options viable for ITER.

The activities described in this paper are key steps toward the development of a ITER prototype pellet injector test stand, which will eventually be used to demonstrate the operating parameters and reliability needed for ITER. First, the development of an improved feed system for an existing centrifuge injector is described. The major objectives of this task are to improve the performance and reliability of this class of injector; this is particularly important since the centrifuge is the base-line ITER concept. Second, the development of a longpulse (up to steady-state) hydrogen extruder feed system is described. This technology is needed to accommodate the 1000-s plasma pulses presently planned for ITER, and the hardware can be customized for used with any acceleration technique. Similarly, the tritium extruder development, which is described last, is relevant for any acceleration scheme, and the hardware has already been used to repetitively form and accelerate 8 -mm-diam deuterium pellets, which represent about a 7\% density perturbation for the large ITER plasma volume.

\section{IMPROVED PELLET FEED SYSTEM FOR CENTRIFUGE INJECTOR}

A major objective of the injector development program at ORNL is to improve the performance and reliability of the centrifuge pellet injection system; this includes pellet reproducibility and the overall pellet delivery reliability. Another development objective is to increase the number of pellets that can be provided for a single machine pulse, with the final goal of steady-state operation (see Sect. III). An existing centrifuge accelerator facility at ORNL provides a test bed for experimental investigations and hardware development. Because the pellet feed system is the key component for 
long-pulse operation, it has received considerable attention over the last few years, with an extensive ORNL development effort on the Zamboni ice machine. A duplicate feed system is used for the pellet injector application on Tore Supra. This unique feed device for the centrifuge accelerator is somewhat limited in performance and thus is not sufficient for the ITER application. Details of this research effort can be found elsewhere [6].

To improve the present centrifuge system, alternative feed systems will be evaluated and can be retrofitted to the existing centrifuge accelerator facility. In the present effort, a standard ORNL extruder and a pellet punch mechanism has been fitted to the existing centrifuge accelerator facility (Fig. 1). The assembly replaced the Zamboni ice machine. The new, punch-type pellet feed/cutter device is close coupled to the arbor and completely adjustable, including the capability to change pellet lengths remotely. The principle of operation is illustrated in Fig. 2, which shows the extruded deuterium ice ribbon and the cutter that produces the pellet and directs it toward the entrance slot of the arbor. As indicated in the illustration, the orientation of the extruder axis is $15^{\circ}$ off the horizontal plane. Because this is significantly different from the standard vertical orientation, a laboratory test that verified the proper fill and operation of the new extruder installation was carried out.

The key component in the new feed is the pellet cutter, and in principle it can operate at frequencies of up to $\sim 50 \mathrm{~Hz}$.
However, the limiting factor will be the rate at which hydrogen ice of satisfactory quality can be provided to the cutting section. The key advantage of the new system is the flexibility incorporated in the design of the components. Four stepping motors allow the cutter to be precisely positioned relative to the arbor entrance slot. Position of individual components can be adjusted during operation to affect the actual pellet orientation exiting the cutter section.

In addition to demonstrating pellet reliability approaching that demonstrated by state-of-the-art pneumatic pellet injection systems $(\geq 98 \%)$, the near-term goals for the operating parameters include (1) pellet frequencies $\geq 10 \mathrm{~Hz}$, (2) pellet speeds $\geq 600 \mathrm{~m} / \mathrm{s}$, (3) pellet sizes in the range of 1 - to $3-\mathrm{mm}$ diameter, and (4) extended pulse lengths with $>400$ pellets available per extruder fill (based on 2.0 -mm-diam by $2.0-\mathrm{mm}$-long cylindrical pellets and a conservative efficiency). Extensive deuterium testing will be carried out to optimize system performance and reliability. The present arbor is limited to pellets $<3 \mathrm{~mm}$ in diameter, and modifications will be required before testing with larger pellets can be carried out. Feed systems that can provide even more pellets to the centrifuge accelerator, including steady-state operation, are also under development and are described next.

\section{STEADY-STATE EXTRUDER FEED}

For the ITER application and future steady-state fusion reactors, a feed system capable of providing a continuous supply

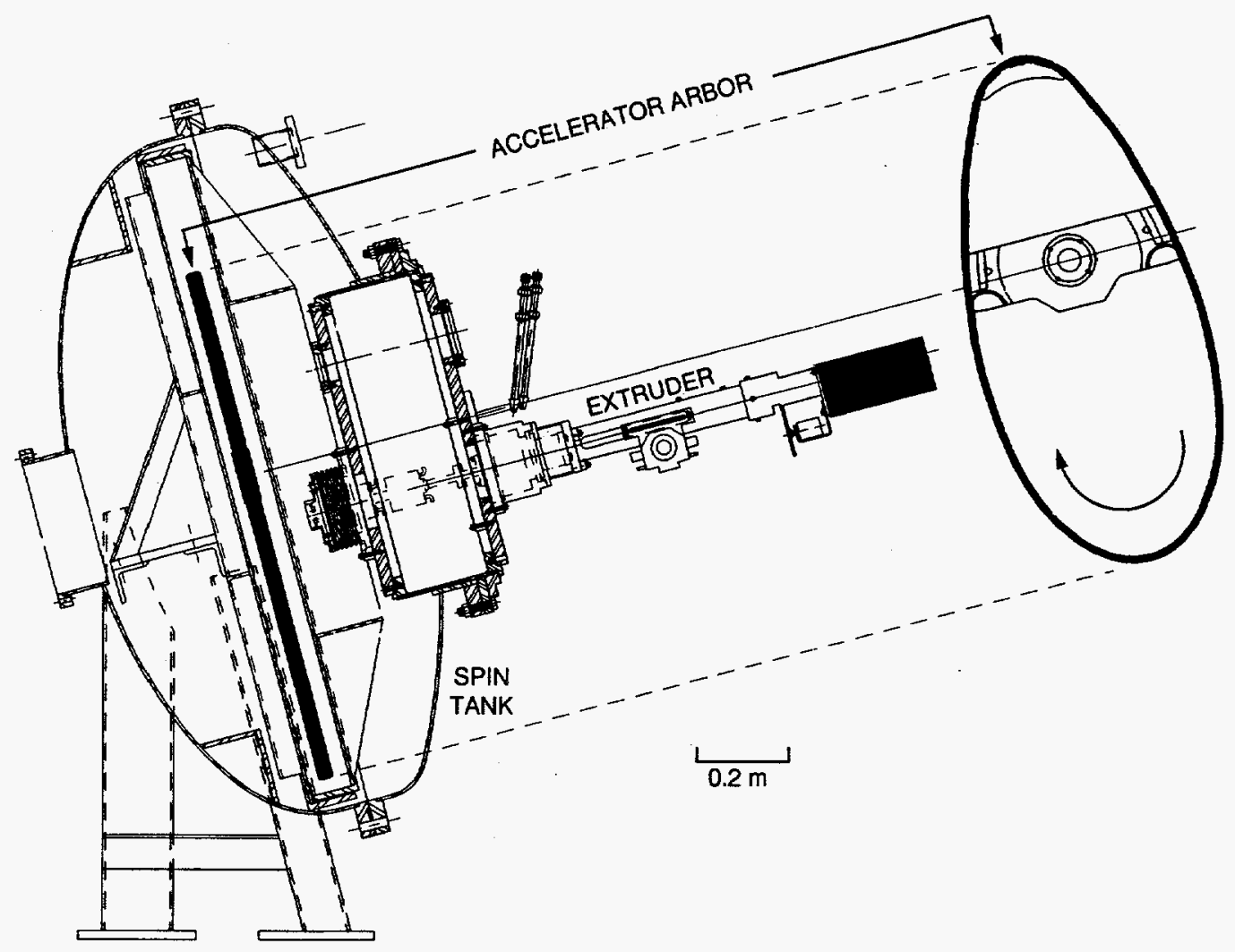

Fig. 1 Side elevation view of ORNL centrifuge pellet injector with new extruder pellet feed system. 


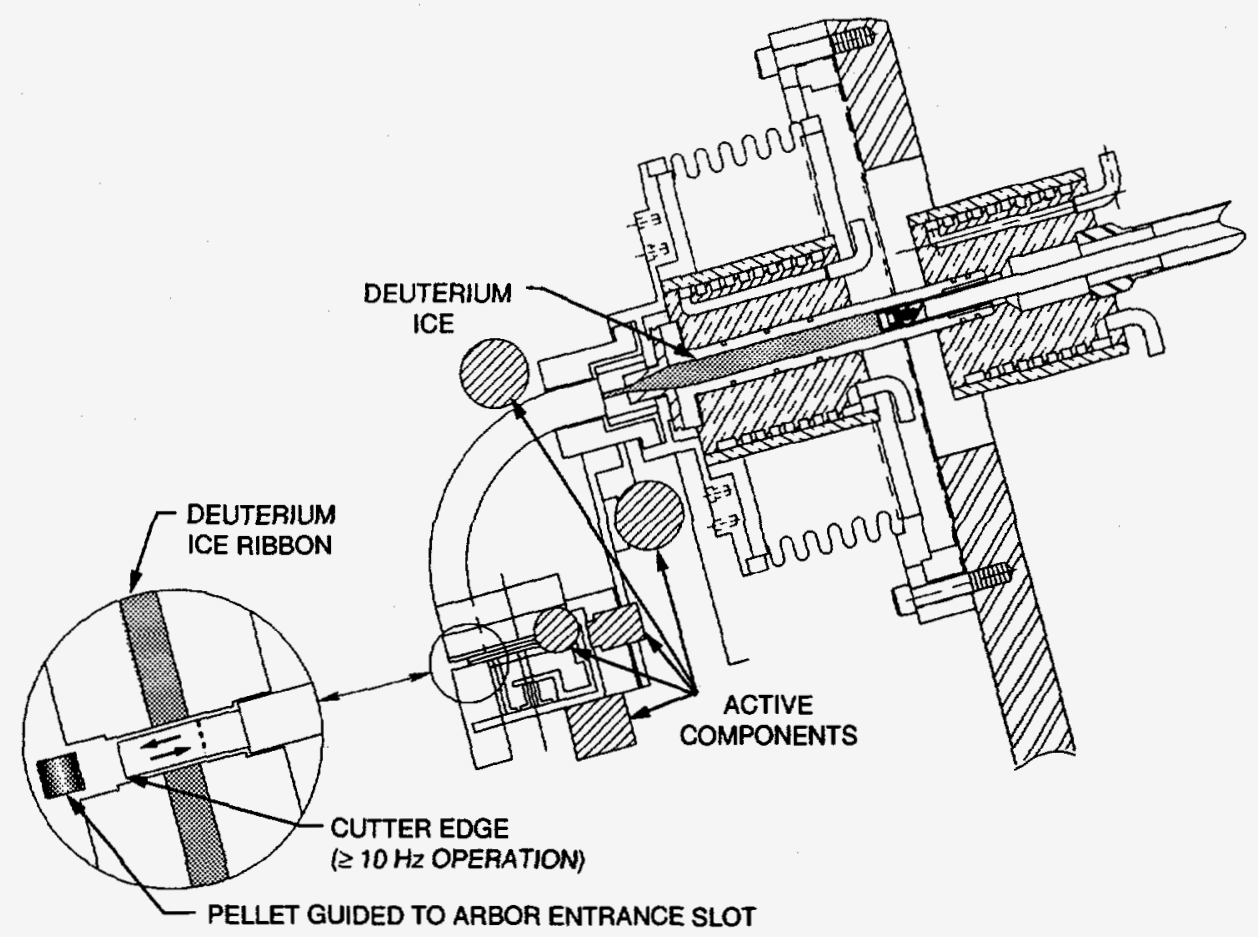

Fig. 2 Close-up view of extruder feed and pellet cutter components (cutting of pellets is illustrated).

of frozen isotopic hydrogen is required. A straightforward technique in which multiple extruder units of identical design operate in tandem (Fig. 3) is being developed for steady-state

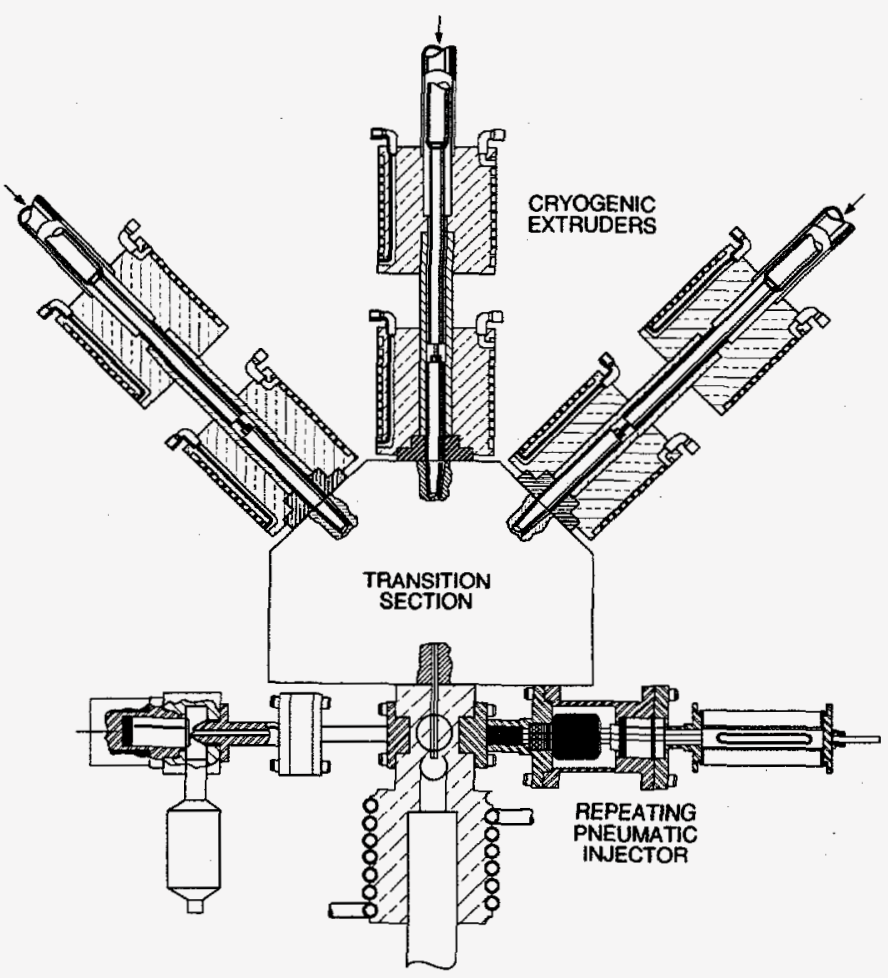

Fig. 3 Schematic of steady-state extruder feed system; three standard extruders operate in tandem to provide a continuous source of frozen hydrogen. operation and should prove adequate for ITER. This approach makes use of a reliable ORNL technology [7,8] that has been used on many pellet injection systems. The overall reliability of this technology is indicated by the performance record of the three-barrel repeating pneumatic injector [5,9-10], which includes three of the standard ORNL extruder units. Since its construction and initial testing in 1986, this system operated on the JET from 1987 to 1992; it was then returned to ORNL for modifications and subsequent installation on the tokamak experiment at General Atomics (DIII-D) in 1994. The system is now fully operational on DIII-D and has been used in experiments. Over a period approaching 10 years, the performance and reliability of the extruders have been outstanding; it is estimated that the three extruders have processed over $5 \mathrm{~kg}$ of deuterium ice in that time period, without any significant problems or mechanical failures.

A prototype consisting of three extruder units is under construction and should be able to provide a continuous source of isotopic hydrogen ice for steady-state operation. In Fig. 3, it is shown feeding a repeating pneumatic injector (RPI); however, the steady-state extruder feed system should be compatible with any acceleration scheme. Instead of using the standard ORNL extruder design, units are under construction in which the volume of available ice is doubled, which gives $\sim 8 \mathrm{~cm}^{3}$ of solid deuterium available per cycle for each unit. The old standard design and the new extruder design are shown in Fig. 4; the only significant change is that the inner diameter of the reservoirs and interconnecting tubing has been increased from 1 to $1.4 \mathrm{~cm}$. A transition piece that accepts the 


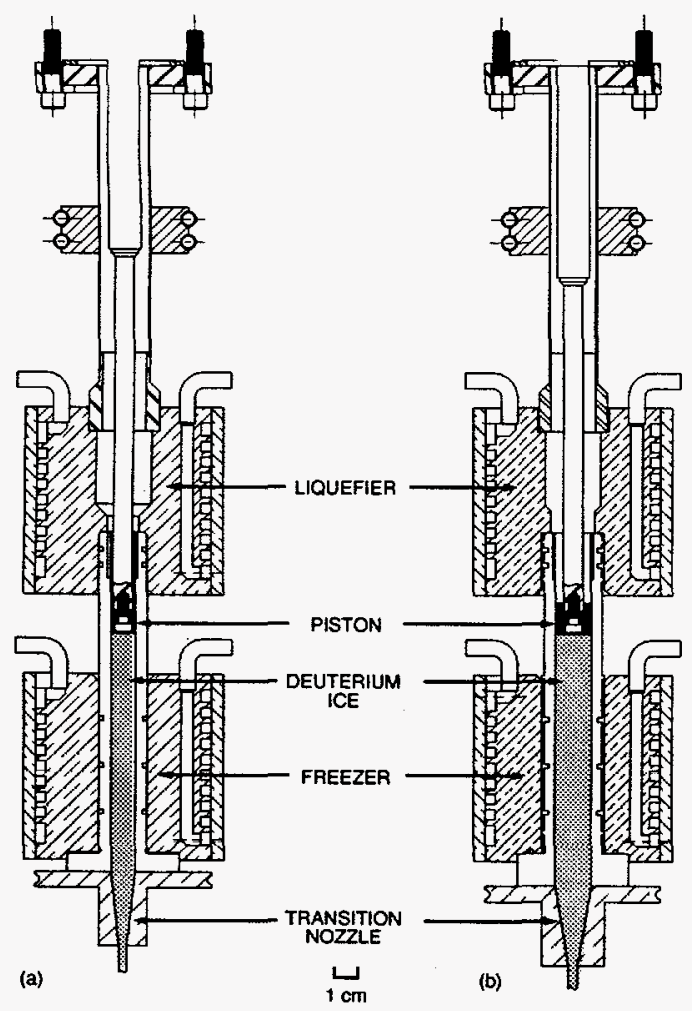

Fig. 4 Designs of (a) standard ORNL extruder and (b) new version with twice the ice volume.

three individual feeds and outputs a single feed is the key new component that must be completed for this design. This component will allow a smooth transition when switching between extruder feeds.

While three extruder units will be used in the prototype, this technique and design could accommodate more extruder units. A control scheme that could easily handle up to six extruder units has already been developed. The extruders are controlled with a National Instruments multiple input and output card (AT-MIO-16X) used in conjunction with a Gateway personal computer. The graphical interface and control software LabView has been used to develop an extruder controller. Multiple copies of the extruder controller can be operated; thus, an operator can control multiple extruders simultaneously. Two extruders can be controlled for each card in the computer. A master controller has been developed to orchestrate the actions of multiple extruders in an automatic control mode, including error messages and interlocks to aid the operator and protect the hardware. In a laboratory experiment, the master controller was successfully tested on a single extruder with deuterium ice and will be used for the final prototype testing.

The equipment described here should be adequate to demonstrate steady-state feed rates required for pellet injector operation at frequencies of up to several hertz (or greater) and pellet sizes in the 2- to 8-mm range. The prototype steady-state extruder feed system could also be used on present long-pulse tokamaks to increase the effective fueling duration.

\section{TRITIUM EXTRUDER TECHNOLOGY}

ORNL has fabricated a pellet injection system to test the mechanical and thermal properties of extruded tritium ice. This repeating single-stage pneumatic injector is called the Tritium-Proof-of-Principle/Phase II (TPOP-II) Pellet Injector and is designed to accommodate larger pellets (nominal 8-mm-diam) than those previously investigated. Physical properties of solid tritium that would facilitate the design and operation of an extruder for tritium are simply not known. The actual behavior of tritium during the extrusion, punching, and acceleration processes must be tested to gain any confidence in the use of extruder-based pellet injectors for ITER. Because of this lack of information, it was decided to utilize the highly successful RPI technology [5,8-10] to get a direct comparison of tritium with the extensive deuterium data base. The goals of the TPOP-II program are (1) to determine the feasibility and conditions under which tritium and D-T mixtures can be extruded, (2) to determine the mechanical and thermal properties of tritium and D-T extrusions, (3) to extrude and accelerate ITER relevant pellets in a repeating mode, (4) to evaluate options for recycling extruder and pellet exhaust, and (5) to evaluate the RPI design in an environment with significant tritium inventory, secondary containment, and interfaces with other tritium processing systems.

An earlier ORNL tritium pellet injector experiment (1988-89) [11-13] at the Tritium Systems Test Assembly (TSTA) at Los Alamos National Laboratory established the basic scientific feasibility of production and pneumatic acceleration of tritium pellets for fueling future fusion reactors [11-13]. The earlier experiment, Tritium-Proof-of-Principle/Phase I (TPOP-I), used a single-stage light gas gun in which single 4-mm-diam pellets were formed in-situ in the barrel and accelerated with high-pressure gas. Over $100 \mathrm{kCi}$ of tritium was processed through the experiment without incident. In Phase II of this experiment, the pipe gun will be replaced with an RPI, which was developed by Combs, Milora, and Foust at ORNL [8]. The specific embodiment of this gun is similar to the design of the injector used on JET $[5,8]$ and recently installed on DIII-D [10]. These extruder-based guns have been used to fuel fusion experiments with deuterium and hydrogen pellet streams ranging from $1.8-\mathrm{mm}$ diameter at $10 \mathrm{~Hz}$ to $6-\mathrm{mm}$ diameter at $1 \mathrm{~Hz}$. The extrusion feed technique is quite general and has also been used for the pellet feed on centrifuge pellet injectors. The TPOP-II gun is designed to produce nominal 8-mm-diam pellets as a prototype for those that will be used to fuel the ITER device. Unlike TPOP-I, which was a single-shot device, the new gun will be able to produce streams of more than ten pellets at frequencies up to $1 \mathrm{~Hz}$. A TPOP-II run could require as much as $50 \mathrm{kCi}(\sim 5 \mathrm{~g})$ of tritium for a single fill of the extruder. 
Fig. 5 is a layout of the TPOP-II experiment as it is installed at TSTA. The tritium extruder, extruder drive, $8-\mathrm{mm}$ gun mechanism, and propellant valve form the RPI gun. The gun is housed in a guard vacuum enclosure that provides a vacuum environment for insulation of the cryogenic systems. A cryogenic ${ }^{3} \mathrm{He}$ separator is also housed in this enclosure. Liquid helium coolant is supplied from portable dewars to the glovebox, and coolant exhaust gas is exhausted from the glovebox to the stack at TSTA. Flow rate of coolant to the various cryostats is controlled by the four helium flow control valves. The injection line contains light gates and photographic stations to record the velocities and integrity of the pellets. With the exception of the gun, essentially all of the original equipment from the TPOP-I experiment will be used to support the TPOP-II experiment. The same glovebox that was used in the original TPOP-I experiment will be used for TPOP-II with the addition of a new section. The new glovebox shown in Fig. 5 has been added above one end of the TPOP-I glovebox to accommodate the extruder drive, which is too tall to fit in the original glovebox. This extension plus the weight of the extruder and guard vacuum box surrounding the RPI required the strengthening of the TPOP glovebox support structure. Shown below the glovebox is a secondarily contained, $\sim 600-\mathrm{L}$ ballast volume to maintain pressure in the injection line below about 50 mbar (38 torr) during pellet production runs. With very few exceptions, tritium-wetted surfaces are all metal (usually stainless steel). All interfaces between the glovebox and TSTA (tritium, deuterium, nitrogen, helium, electrical, control, vacuum connections, etc.) are through panels in the top of the glovebox. Cajon VCR fittings are used for all external gas connections in these panels. Operation of the entire experiment is controlled remotely from a central console. High-speed data acquisition for pellet diagnostics is accomplished through a MicroVAX II computer and CAMAC interfaces located at the back of the control console.

At TSTA, tritium will be supplied to the experiment from a product container (PC) mounted in the load-in/load-out (LIO) glovebox. Much larger tritium throughputs are anticipated for TPOP-II than were required in the earlier TPOP-I experiments; therefore, the base-line approach will include recycling of extruder and injection line exhaust gas streams within the TPOP manifold system to maximize experimental output within TSTA constraints of tritium supply and tritiated gas storage.

TPOP-II injector was fabricated and operated at ORNL prior to shipment to TSTA in March 1995. During this period it was used to produce deuterium pellets that were accelerated with hydrogen propellant. Fig. 6 shows one of the early deuterium pellets produced by the gun. After acceleration these pellets were typically $7.4 \mathrm{~mm}$ in diameter by $11 \mathrm{~mm}$ long and

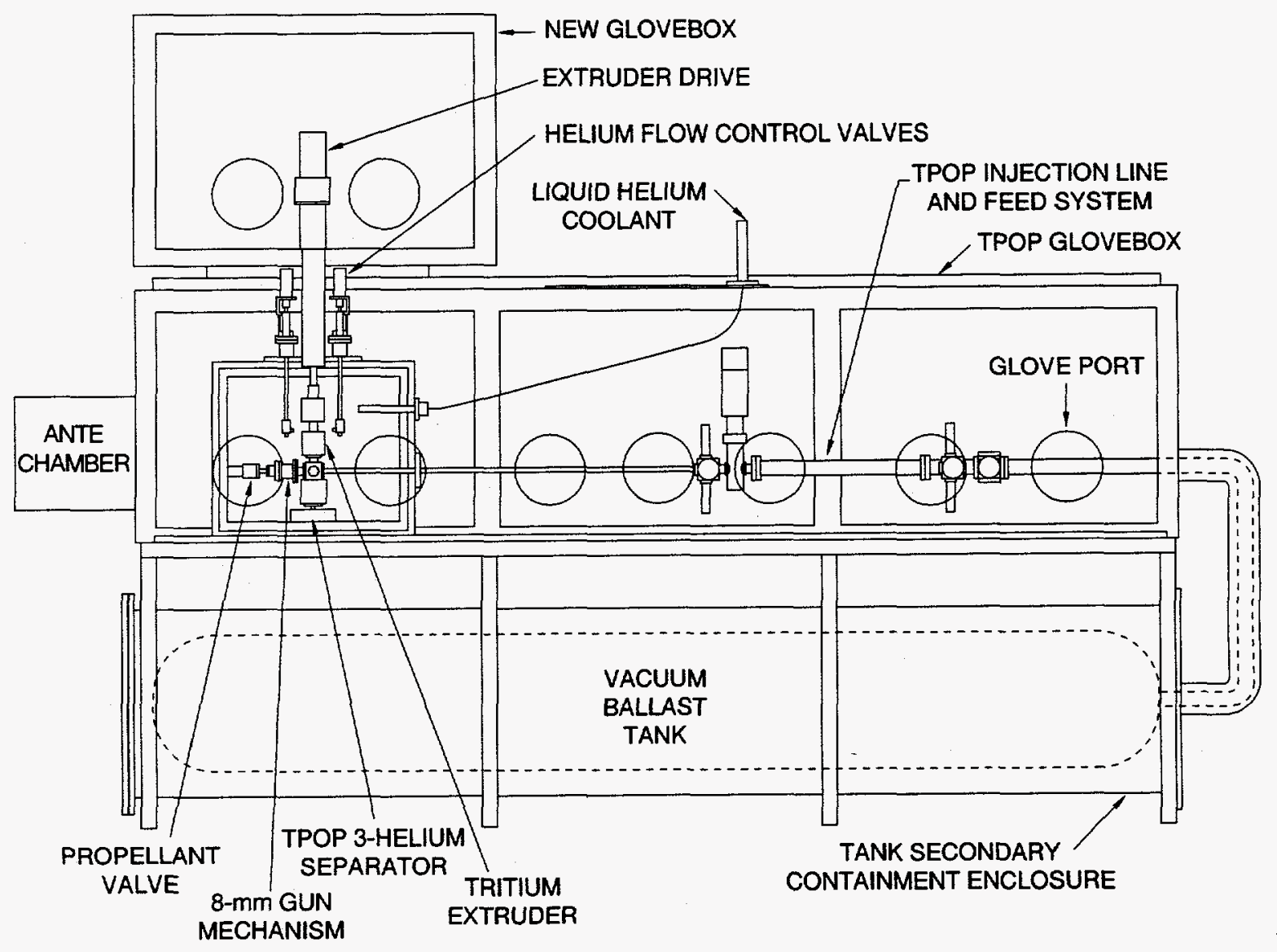

Fig. 5 Schematic of TPOP-II pellet injector (repeating single-stage light gas gun in glovebox for tritium pellet operations). 


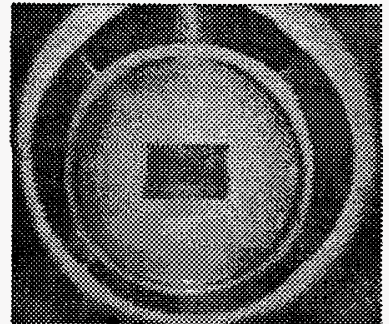

Fig. 6 Photograph of 7.4-mm-diam by $11-\mathrm{mm}$-long deuterium pellet formed and accelerated with TPOP-II repeating pneumatic injector (pellet speed of $1.1 \mathrm{~km} / \mathrm{s})$.

traveled at speeds of $\sim 1 \mathrm{~km} / \mathrm{s}$. These pellets would represent about a $11 \%$ density perturbation to ITER. Subsequently, the extruder nozzle was modified to produce a pellet with an accelerated aspect ratio of about one. Fig. 7 shows a sequence of these pellets, which would represent about a 7\% density perturbation in ITER. During commissioning with deuterium feed at ORNL, the extruder and injection line diagnostics were optimized for proper operation, and the CAMAC-based data acquisition and fast control system was developed and tested for operation at pellet frequencies up to $1 \mathrm{~Hz}$. Strings of up to 13 pellets have been extruded, punched at rates up to $1 \mathrm{~Hz}$, and accelerated to speeds of 1.0 to $1.1 \mathrm{~km} / \mathrm{s}$, using hydrogen propellant gas at a supply pressure of 65 bar. The quality of the extruded ice and accelerated pellets was evaluated as a function of extrusion speed, repetition rates, feed pressure, cryostat temperatures, and timing sequence between the punch and propellant valve. In initial testing at TSTA, deuterium pellets $(7.4 \mathrm{~mm}$ diam by $\sim 8 \mathrm{~mm}$ long) were successfully extruded at rates up to $0.3 \mathrm{~Hz}$ and accelerated to speeds in the $600-$ to $800-\mathrm{m} / \mathrm{s}$ range with deuterium propellant gas.

\section{DISCUSSION}

As noted earlier, one requirement for the ITER fueling system is to control gas composition in the plasma edge. This point is important to the development of the concept of isotopic tailoring [14]. In this concept, pellets of high-tritium concentration would be delivered beyond the divertor scrape-off layer for plasma fueling, and gas of high-deuterium concentration would be delivered into the scrape-off layer to control the density and composition of the divertor region. The high concentration of deuterium next to the wall would translate into lower tritium concentration in the wall and would significantly reduce the tritium inventory in the wall, which could approach $10 \mathrm{~kg}$ without tailoring.

Fueling requirements for ITER have not been fully established at this time, but early concepts [1] called for the use of up to 8-mm-diam D-T pellets (and possibly even larger pellets) at a rate of $1 \mathrm{~Hz}$. The largest 8-mm pellets in the present experimental study ( $11 \mathrm{~mm}$ long) would represent about a $11 \%$ perturbation in the plasma density if the entire mass were deposited in the core. More recent estimates of fueling requirements call for smaller pellets at higher repetition rates. With the flexibility that the centrifuge and pneumatic acceleration technologies offer and the supporting development activities discussed in this paper, pellet fueling systems capable of meeting the ITER operating requirements should be demonstrated within the next few years.
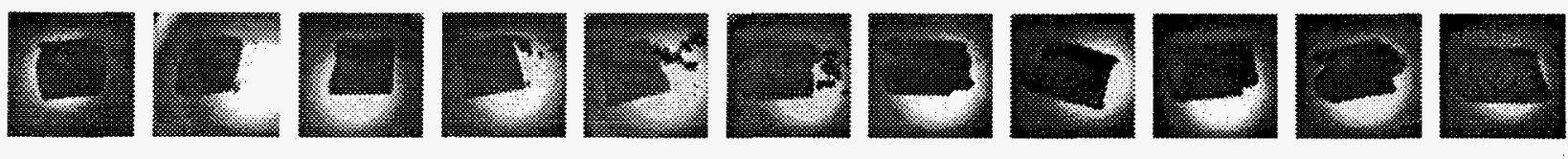

Fig. 7 Photographs of a sequence of deuterium pellets from TPOP-II injector (pellets fired from 8-mm-diam bore at $0.5 \mathrm{~Hz}$ and $-1 \mathrm{~km} / \mathrm{s}$ ).

\section{REFERENCES}

[1] M. J. Gouge, K. D. St. Onge, S. L. Milora, P. W. Fisher, and S. K. Combs, "Pellet Fueling System for ITER," Fusion Engineering and Design 19(1), 53-72 (July 1992).

[2] S. L. Milora, "Review of Pellet Fueling," J. Fusion Energy 1, 15 (1981).

[3] S. K. Combs, "Pellet Injection Technology," Rev. Sci. Instrum. 64, 1679 (1993).

[4] S. L. Milora, W. A. Houlberg, L. L. Lengyel, and V. Mertens, "Pellet Fuelling," Nuclear Fusion 35, 657 (1995).

[5] S. K. Combs, T. C. Jernigan, L. R. Baylor, S. L. Milora, C. R. Foust, P. Kupschus, M. Gadeberg, and W. Bailey, "Performance of a Pneumatic Hydrogen-Pellet Injection System on the Joint European Torus," Rev. Sci. Instrum. 60, 2697 (1989).

[6] C. A. Foster et al., "ORNL Centrifuge Pellet Fueling System," in: Fusion Technology 1992: Proc. 17th Symposium, Rome, 14-18 September 1992 (North-Holland, Amsterdam), Vol. I, p. 496.

[7] C. A. Foster, J. Vac. Sci. Technol. A1, 952 (1983).

[8] S. K. Combs, S. L. Milora, C. R. Foust, C. A. Foster, and D. D. Schuresko, "Repeating Pneumatic Hydrogen Pellet Injector for Plasma Fueling," Rev. Sci. Instrum. 56, 1173 (1985).
[9] S. K. Combs, S. L. Milora, L. R. Baylor, C. R. Foust, F. E. Gethers, and D. O. Sparks, "A Three-Barrel Repeating Pneumatic Pellet Injector for Plasma Fueling of the Joint European Torus," J. Vac. Sci. Technol. A6, 1901 (May/June 1988).

[10] S. K. Combs, C. R. Foust, and S. L. Milora, "Small-Bore (1.8-mm), High-Firing-Rate (10-Hz) Version of Repeating Pneumatic Hydrogen Pellet Injector," Rev. Sci. Instrum. 66, 2736 (1995).

[11] P. W. Fisher et al., "Tritium Proof-of-Principle Injector Experiment," Fusion Technol. 14, 977 (1988).

[12] P. W. Fisher et al., "Tritium Pellet Injector Results," J. Vac. Sci. Technol. 7, 939 (1989).

[13] P. W. Fisher, D. T. Fehling, and S. L. Milora, "Tritium Proof-ofPrinciple Pellet Injector Results," IEEE Proc. of the 13th Symp. on Fusion Engr., Knoxville, Vol. 2, p. 1236, IEEE 89CH2820-9, Institute of Electrical and Electronics Engineers, New York, 1989.

[14] M. J. Gouge et al., "Fuel Source Isotopic Tailoring and Its Impact on ITER Design, Operation, and Safety," unpublished. 


\section{DISCLAMMER}

Portions of this document may be illegible in electronic image products. Images are produced from the best available original document. 